\title{
Clinical Competence of Undergraduate Dental Students in Pediatric Dentistry at a Saudi Dental School
}

\author{
Sanaa N. Al-Haj Ali1 10
}

${ }^{1}$ Department of Orthodontic and Pediatric Dentistry, College of Dentistry, Qassim University, Qassim, Saudi Arabia.

Correspondence: Sanaa N. Al-Haj Ali, Department of Orthodontic and Pediatric Dentistry, College of Dentistry, Qassim University, Qassim, Saudi Arabia, PO Box 6700, Postal Code 51452. E-mail: dr.sanaa.alhajali@qudent.org

Academic Editor: Alessandro Leite Cavalcanti

Received: 20 October 2020 / Review: 08 December 2020 / Accepted: 18 January 2021

How to cite: Al-Haj Ali SN. Clinical competence of undergraduate dental students in pediatric dentistry at a Saudi dental school. Pesqui Bras Odontopediatria Clín Integr. 202 1; 2 1:e0226. https://doi.org/10.1590/pboci.202 1.078

\begin{abstract}
Objective: To assess the clinical competence of undergraduate dental students in pediatric dentistry at Qassim University dental school. Material and Methods: A retrospective audit of students' clinical competency sheets of fourth and fifth-year students $(n=102)$ over two years was performed. Mean competency scores for each clinical procedure as well as overall scores of the students were compared according to their academic level and gender. Also, the percentage of competent students was compared according to the academic level. Chi-square and t-tests were used to analyze the data $(p<0.05)$. Results: Compared to fifth-year students, fourth-year students were significantly more competent in pediatric dentistry $(100 \%$ scored $>50 \%$ overall compared to $86.9 \%$ of fifth-year students). They had significantly higher mean overall scores $(84.63 \pm 9.15$ compared to $67.68 \pm 13.83)$ as well as individual scores in performing an examination, diagnosis, and treatment planning of a child patient, restorations, and stainless steel crowns than fifth-year students. In addition, females had significantly higher mean scores in the aforementioned procedures and in placing esthetic crowns $(\mathrm{p}<0.05)$. Conclusion: Fourth-year dental students at Qassim University were more competent clinically than fifth-year students in pediatric dentistry. Also, in most of the shared procedures, females were more competent than males. A deficiency in the competence of fifth-year students was noted in pulp therapy, stainless steel and esthetic crowns procedures, and these are currently being addressed.
\end{abstract}

Keywords: Quality of Health Care; Clinical Competence; Students, Dental; Pediatric Dentistry. 


\section{Introduction}

According to the World Health Organization (WHO), dental caries is the most common noncommunicable disease worldwide [1]. Several studies have reported that it is prevalent in Saudi Arabia, with estimates reaching $83 \%$ [2-4]. Without treatment, many of those affected children with dental caries will undergo disease progression, and that will subsequently affect the quality of life in these children. Also, the chances of hospitalizations to have dental treatment under general anesthesia will perhaps increase [5]. This consequently highlights a need for general dentists to address the problem of providing routine dental care for children, particularly after considering that they are more available and accessible than specialist pediatric dentists to the public [6]. Undergraduate dental education in pediatric dentistry has been suggested, by some reports, as a starting point to ensure that future general dentists receive sufficient educational and clinical experiences concerning the treatment of children [ $[7,8]$.

At Qassim University dental school, training in pediatric dentistry follows a competency-based track. Novice students begin training in simulation laboratories to prepare them for the beginner and competent levels to be obtained in clinical settings. Preclinical training in pediatric dentistry is given to dental students in the first term of their fourth year, along with a theoretical course in pediatric dentistry. These are followed by the beginner level of competency-based clinical training in pediatric dentistry during the second term of the fourth year. All fourth-year students have to prove competent in the beginner level to be eligible to commence the competent level, which starts in the fifth year and consists of different clinical requirements.

Although recommendations are available regarding clinical skills and competencies to be achieved in predoctoral dental education [9,10], few published studies focused on dental students' clinical competence in pediatric dentistry during the undergraduate level [11-15], and these were conducted in non-Saudi institutions

Therefore, the objective of the present study was to assess the clinical competence of undergraduate dental students in pediatric dentistry at Qassim University dental school.

\section{Material and Methods}

Study Design and Sample

A retrospective audit of students' clinical competency sheets $(n=102)$ - after being cross-checked with clinical supervisors and patients' files- of 102 fourth and fifth-year dental students at Qassim University dental school in the academic years 2018-2020 was performed in August 2020.

\section{Data Collection}

In their fourth year, dental students were supposed to pass the beginner level. At this level, students were requested to provide a certain number of predetermined clinical procedures to child patients under the supervision of specialist faculty members in pediatric dentistry in three-hour-interval sessions. During the session, the supervising faculty member observed all the steps involved in the clinical procedure(s) performed by the student. The same approach was followed for fifth-year students at the competent level; however, the type and/or the number of clinical procedures requested from fifth-year students was different.

A description of each competency level (beginner and competent) and the clinical procedures involved in it, as well as minimum scores required in each clinical procedure, are summarized in Tables 1 and 2. 
Table 1. Number of clinical procedures in pediatric dentistry, which is required at the beginner level and the minimum score required in each procedure.

\begin{tabular}{|c|c|c|c|}
\hline Item\# & Procedure & Cases Required & $\begin{array}{c}\text { Minimum Score } \\
\text { Required }\end{array}$ \\
\hline \multirow[t]{2}{*}{1} & Examination, diagnosis, and treatment planning for a child patient & Case 1 & $75 \%$ \\
\hline & & Case 2 & $80 \%$ \\
\hline \multirow[t]{6}{*}{2} & Restorations & Case 1 & $65 \%$ \\
\hline & & Case 2 & $70 \%$ \\
\hline & & Case 3 & $75 \%$ \\
\hline & & Case 4 & $75 \%$ \\
\hline & & Case 5 & $80 \%$ \\
\hline & & Case 6 & $80 \%$ \\
\hline \multirow[t]{2}{*}{3} & Pulp therapy of primary teeth (pulpotomy or pulpectomy) & Case 1 & $75 \%$ \\
\hline & & Case 2 & $80 \%$ \\
\hline \multirow[t]{2}{*}{4} & Stainless steel crown of a primary molar & Case 1 & $75 \%$ \\
\hline & & Case 2 & $80 \%$ \\
\hline \multirow[t]{3}{*}{5} & Extractions & Case 1 & $70 \%$ \\
\hline & & Case 2 & $75 \%$ \\
\hline & & Case 3 & $80 \%$ \\
\hline
\end{tabular}

Table 2. Number of clinical procedures in pediatric dentistry, which are required in the competent level and the minimum score required in each procedure.

\begin{tabular}{|c|c|c|c|}
\hline Item\# & Procedure & Cases Required & $\begin{array}{c}\text { Minimum Score } \\
\text { Required }\end{array}$ \\
\hline \multirow[t]{2}{*}{1} & Examination, diagnosis, and treatment planning for a child patient & Case 1 & $75 \%$ \\
\hline & & Case 2 & $80 \%$ \\
\hline \multirow[t]{4}{*}{2} & Restorations & Case 1 & $65 \%$ \\
\hline & & Case 2 & $70 \%$ \\
\hline & & Case 3 & $75 \%$ \\
\hline & & Case 4 & $80 \%$ \\
\hline \multirow[t]{5}{*}{3} & Pulp therapy of primary teeth (pulpotomy or pulpectomy) & Case 1 & $65 \%$ \\
\hline & & Case 2 & $70 \%$ \\
\hline & & Case 3 & $75 \%$ \\
\hline & & Case 4 & $75 \%$ \\
\hline & & Case 5 & $80 \%$ \\
\hline \multirow[t]{5}{*}{4} & Stainless steel crown of a primary molar & Case 1 & $65 \%$ \\
\hline & & Case 2 & $70 \%$ \\
\hline & & Case 3 & $75 \%$ \\
\hline & & Case 4 & $75 \%$ \\
\hline & & Case 5 & $80 \%$ \\
\hline 6 & Space maintainers & Case 1 & $80 \%$ \\
\hline 7 & Esthetic crowns & Case 1 & $80 \%$ \\
\hline
\end{tabular}

*Item number 5 (extractions) not required from the fifth-year students.

Table 3 provides a summary of the assessment criteria for each clinical procedure involved in these levels. According to these predetermined assessment criteria, each student was awarded a grade (out of 100) by the supervisor for each clinical procedure on a prepared competency sheet specific to that level. Each clinical procedure had its prepared rubric sheet, which included an explanation of how the evaluation was given to the students by their clinical supervisors in each clinical procedure.

The rubric sheet of the clinical procedure: examination, diagnosis, and treatment planning of a child patient is given as an example on adopted rubric sheets in Table 4.

Overall, a student was deemed competent in the respective level if the student's overall score of the required clinical procedures was more than 50. All competency levels and their respective assessment sheets and rubrics were approved by the Department of Orthodontic and Pediatric Dentistry faculty members and Qassim University College of Dentistry council. 
Table 3. Assessment criteria and scores of the clinical procedures involved in the beginner and competent levels.

\begin{tabular}{|c|c|c|c|c|c|c|c|}
\hline Item\# & & & & essment Criteria & & & \\
\hline 1 & History taking / 10 & Examination /20 & Radiographic Diagnosis / 10 & Treatment Planning /20 & Behavior guidance $/ 15$ & Case presentation $/ 15$ & Time /10 \\
\hline 2 & Anesthesia / 10 & Isolation / 10 & Behavior guidance / 10 & Cavity preparation /30 & Restoration / 30 & Time $/ 1$ & \\
\hline 3 & Anesthesia / 10 & Isolation / 10 & Behavior guidance / 10 & Access $/ 40$ & Restoration /20 & Time / & \\
\hline 4 & Anesthesia / 10 & Isolation / 5 & Behavior guidance / 10 & Tooth preparation /30 & Crown selection and ad & ptation $/ 25$ & tion $/ 10$ \\
\hline 5 & Anesthesia / 10 & Behavior guidance / 20 & Procedure/ 50 & Time $/ 10$ & Post-ol & rative instructions / 10 & \\
\hline 6 & Band selection /20 & $\begin{array}{l}\text { Impression and band } \\
\text { placement } / 40\end{array}$ & Cementation /20 & Behavior guidance / 10 & & Time / 10 & \\
\hline 7 & Anesthesia / 10 & Isolation / 10 & Behavior guidance/ 10 & Tooth preparation/30 & Crown adaptation $/ 20$ & Restoration / 10 & Time / 10 \\
\hline
\end{tabular}

Table 4. Rubric for performing an examination, diagnosis, and treatment planning for a child patient.

\begin{tabular}{|c|c|c|c|c|c|}
\hline Assessment Criteria & Excellent* $(9-10 / 10)$ & Good* $(7-8 / 10)$ & Fairt $^{(5-6 / 10)}$ & Fail $^{\ddagger}(0-5 / 10)$ & Score \\
\hline History taking & $\begin{array}{l}\text {-Complete personal data } \\
\text {-Medical history checked } \\
\text {-Dental history checked } \\
\text {-Caries risk assessment performed. }\end{array}$ & $\begin{array}{l}\text {-Complete_personal da } \\
\text {-Medical history check } \\
\text {-Caries risk assessmen }\end{array}$ & rformed. & & $/ 10$ \\
\hline Examination & $\begin{array}{l}\text {-Complete extra and intraoral examination. } \\
\text {-Occlusion checked and orthodontic evaluation performed. } \\
\text {-Accurate dental charting. }\end{array}$ & $\begin{array}{l}\text { - Complete extra and i } \\
\text {-Occlusion checked an } \\
\text {-Accurate dental chart }\end{array}$ & $\begin{array}{l}\text { oral examination. } \\
\text { thodontic evaluation }\end{array}$ & ormed. & 120 \\
\hline Radiographic Diagnosis & $\begin{array}{l}\text {-Indicated radiographs are taken. } \\
\text {-Quality of bone, tooth structure, and development was examined. } \\
\text {-Proximal regions of teeth examined. }\end{array}$ & $\begin{array}{l}\text {-Indicated radiographs } \\
\text {-Proximal regions of t }\end{array}$ & $\begin{array}{l}\text { taken. } \\
\text { examined. }\end{array}$ & & $/ 10$ \\
\hline Treatment Planning & $\begin{array}{l}\text {-Prevention of caries emphasized in the initial appointment. } \\
\text {-Quadrant dentistry practiced. } \\
\text {-Accurate plan for restoration. } \\
\text {-Appliances kept last in treatment. } \\
\text {-Recall period given according to the patient's disease risk. }\end{array}$ & $\begin{array}{l}\text {-Prevention of caries e } \\
\text {-Accurate plan for rest } \\
\text {-Recall period given ac }\end{array}$ & $\begin{array}{l}\text { lasized in the initial at } \\
\text { tion. } \\
\text { ding to the patient's } d\end{array}$ & $\begin{array}{l}\text { ntment. } \\
\text { se risk. }\end{array}$ & 120 \\
\hline Behavior Guidance & -All behavior management techniques were used. & $\begin{array}{l}\text {-Three behavior } \\
\text { management } \\
\text { techniques were used. }\end{array}$ & $\begin{array}{l}\text {-Only one behavior } \\
\text { management } \\
\text { technique was used. }\end{array}$ & $\begin{array}{l}\text { - No behavior } \\
\text { management } \\
\text { techniques were used. }\end{array}$ & $/ 15$ \\
\hline Case Presentation & $\begin{array}{l}\text {-Disclosed sufficient information. } \\
\text {-Optimum treatment for the problems with benefits and risks discussed. } \\
\text {-Alternative treatment with benefits and risks were given. } \\
\text {-Number of required visits and duration given. } \\
\text {-Preventive means given and anticipatory guidance practiced. } \\
\text {-Signed consent form. }\end{array}$ & $\begin{array}{l}\text {-Disclosed sufficient in } \\
\text {-Optimum treatment } \mathrm{f} \\
\text {-Alternative treatment } \\
\text {-Preventive means giv } \\
\text {-Signed consent form. }\end{array}$ & $\begin{array}{l}\text { nation. } \\
\text { he problems with bene } \\
\text { h benefits and risks w } \\
\text { nd anticipatory guida }\end{array}$ & $\begin{array}{l}\text { and risks discussed. } \\
\text { given. } \\
\text { practiced. }\end{array}$ & $/ 15$ \\
\hline Time & $<60$ minutes & $60-120$ minutes & 120-180 minutes & $>180$ minutes & $/ 10$ \\
\hline
\end{tabular}

*All items performed; $\uparrow$ Mistake in one item; ${ }_{+}^{+}$Mistake in more than one item. 
Statistical Analysis

Data were recorded on a Microsoft Excel sheet, and statistical analysis was performed using the SPSS computer software, version 22.0 (SPSS Inc., Chicago, IL, USA). Mean competency scores (out of 100) for each clinical procedure in each competency level, as well as overall competency scores of the students, were compared according to the academic level and gender. The percentage of competent students in the clinical procedures and each competency level was compared according to students' academic level. Chi-square and ttests were used to analyze the data $(\mathrm{p}<0.05)$.

\section{Results}

Mean competency scores of the students in each clinical procedure and total score according to the academic level and gender of the students are shown in Table 5, while Figure 1 shows the percentage of competent students in each clinical procedure and total procedures according to the academic level. When the scores of the students are compared according to the academic level, fourth-year students were found to have significantly higher mean overall competency scores $(84.63 \pm 9.15)$ compared to fifth-year students $(67.68 \pm$ 13.83). Also, they had significantly higher mean competency scores in the individual clinical procedures: examination, diagnosis and treatment planning of a child patient, restorations, and stainless steel crowns for primary molars than fifth-year students $(\mathrm{p}<0.05)$. All fourth-year students were found to be competent at the beginner level (scored $>50$ ), while about $86.9 \%$ of fifth-year students were competent in the competent level (13.1\% of them incompetent), being significantly less competent than fourth-year students. In addition, fourthyear students were significantly more competent than fifth-year students in performing restorations, pulp therapy procedures, and stainless steel crowns for primary molars $(\mathrm{p}<0.05)$.

Table 5. Mean competency scores for each clinical procedure and total score according to the academic level and gender of the students $(n=102)$.

\begin{tabular}{lccccccc}
\hline \multirow{2}{*}{ Item \# } & \multicolumn{2}{c}{ Academic Level } & p-value & \multicolumn{3}{c}{ Gender } \\
& Fourth-year $(\mathrm{N}=41)$ & Fifth-year $(\mathrm{N}=61)$ & & Males $(\mathrm{N}=27)$ & Females $(\mathrm{N}=75)$ & p-value \\
\hline 1 & $88.62 \pm 2.79$ & $85.81 \pm 16.70$ & $0.002^{*}$ & $80.12 \pm 22.29$ & $89.40 \pm 5.94$ & $<0.001^{*}$ \\
2 & $82.80 \pm 17.36$ & $72.49 \pm 24.36$ & $0.001^{*}$ & $63.10 \pm 27.51$ & $81.51 \pm 17.96$ & $0.002^{*}$ \\
3 & $79.47 \pm 21.58$ & $74.86 \pm 23.00$ & 0.133 & $77.14 \pm 22.16$ & $76.56 \pm 22.70$ & 0.912 \\
4 & $83.96 \pm 17.93$ & & $68.76 \pm 26.38$ & $<0.001^{*}$ & $66.01 \pm 27.60$ & $78.06 \pm 22.54$ & $0.017^{*}$ \\
6 & & $\mathrm{NA}$ & & - & $48.51 \pm 8.55$ & $51.58 \pm 8.01$ & 0.183 \\
7 & & $\mathrm{NA}$ & & - & $19.70 \pm 7.24$ & $35.58 \pm 7.87$ & $0.002^{*}$ \\
Overall & $84.63 \pm 9.15$ & & $67.68 \pm 13.83$ & $<0.001^{*}$ & $63.51 \pm 13.18$ & $78.45 \pm 13.21$ & 0.921 \\
\hline * & & & & &
\end{tabular}

*Statistically Significant; Extractions (mean \pm SD): $89.56 \pm$ 2.68; NA: Not Applicable.

On the other hand, when the scores of the students were compared according to gender, females were found to have significantly higher mean competency scores in the clinical procedures; examination, diagnosis, and treatment planning of a child patient, restorations, stainless steel crowns for primary molars, and esthetic crowns $(\mathrm{p}<0.05)$. Females also had a higher mean overall score than males; however, the difference was not statistically significant $(\mathrm{p}>0.05)$. 


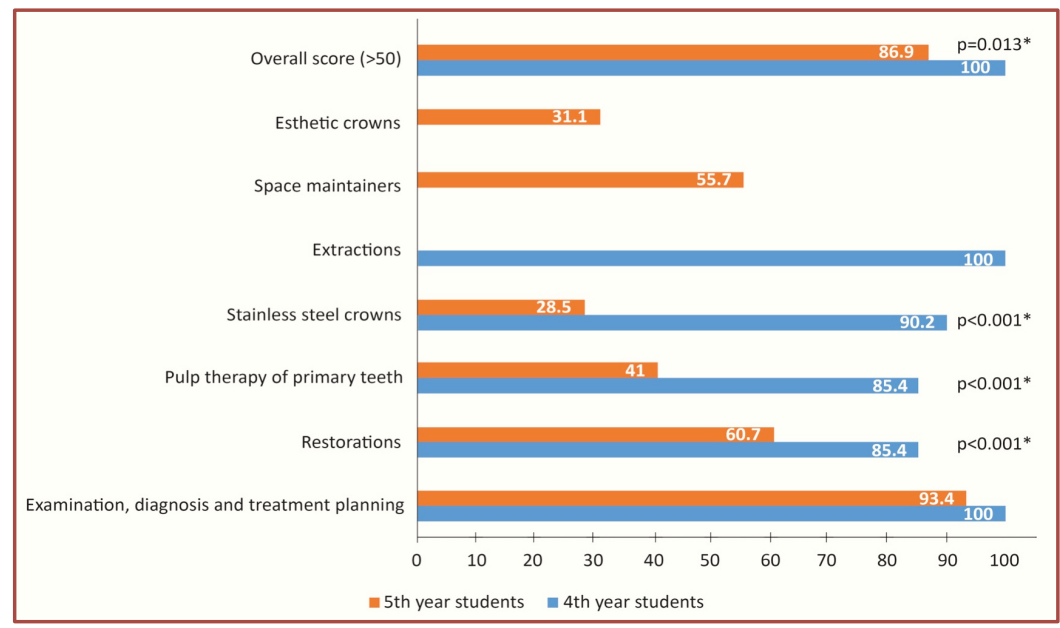

Figure 1. Percentage of competent students in each clinical procedure and total procedures (whole competency level) according to the academic level (extractions not applicable to 5th-year students and Space maintainers and esthetic crowns not applicable to 4th-year students).

\section{Discussion}

The present study is the first to assess the competence of undergraduate dental students in pediatric dentistry at a Saudi dental school. As with all dental schools, Qassim University dental school tries its best to achieve the learning outcomes of the curriculum it is delivering to dental students to provide the dental market with graduates who have sufficient knowledge and clinical skills in pediatric dentistry in the current example. However, difficulties are still faced concerning the availability of sufficient resources and a pool of child patients with proper case mix. The findings of the present study demonstrate that some deficiency in the competence of undergraduate dental students in pediatric dentistry is present, mainly of the fifth year (final year) dental students. Deficiencies in the competence of undergraduate dental students in pediatric dentistry were also reported in Jordan [11] and the UK [12], particularly with regards to the management of dentoalveolar traumatic injuries. Dentoalveolar traumatic injuries were not enlisted among the required (compulsory) clinical procedures of either the beginner or competent levels at Qassim University dental school due to their rarity in the region.

In the present study, the clinical procedures in which fifth-year students were incompetent included: pulp therapy procedures, stainless steel crowns for primary molars, and esthetic crowns, as less than $50 \%$ of fifth-year students prove to be competent in these clinical procedures. Rodd et al. [12] also reported less exposure of dental students to pulp therapy and stainless steel crowns procedures along with dental trauma cases as compared to other procedures. According to these authors, those procedures are among the procedures that students are only expected to know about them and thus need only have limited clinical experience. That, to some extent, seems to apply as well to esthetic crowns' procedures. However, strategies to improve students' exposure, particularly to pulp therapy and stainless steel crowns procedures, are necessary and should be implemented.

One important explanation for the deficiency in the clinical competence of fifth-year students, as compared to fourth-year students, is the likelihood that a good proportion of them was facing patients with complex treatment needs or young and apprehensive children. This seems to be very likely the case, particularly when the prevalent nature of dental caries in children is considered in Saudi Arabia [Q2-4]. Compared to fourth-year students, fifth-year students had a larger number of cases of pulp therapy and stainless steel crown procedures ( 5 cases compared to 2 cases for fourth-year students) required from them. 
Fifth-year students were also requested to perform an esthetic crown case, while that was not required from fourth-year students. This, in turn, can explain the greater difficulty faced by a good proportion of fifth-year students to accomplish the number of required cases from them in these procedures. While completing the exact number of cases of those procedures was not mandatory for fifth-year students to pass the competent level, as long as their overall score of the level exceeded 50. This still affected the overall score of some of the fifth-year students, particularly those who had a deficiency of more than one pulp therapy or stainless steel crown case and pass scores only in the rest of their performed clinical procedures.

Another point to consider is that preventive procedures were not a component of the competent level for fifth-year students. One advantage of performing preventive procedures (e.g., fluoride applications, fissure sealants, and dental prophylaxis), whenever applicable, is the establishment of rapport between the dentist and child patient by introducing the child, particularly the young and apprehensive one- to dentistry through minimal and less invasive procedures being performed in the first visit [14]. According to the American Academy of Pediatric Dentistry (AAPD), a child's first dental visit should be at the time of the eruption of the first primary tooth and no later than 12 months of age [15]; however, many children who received dental care by the students at Qassim University dental clinics were way beyond this age, and their dental visits to Qassim University dental clinics were their very first visits. Consequently, it can be assumed that fifth-year students avoided doing preventive procedures for those children as they are not part of the clinical procedures of the competent level, and investing their time in them, without counting the cases for them, would be a waste of time. This issue is currently being addressed by Qassim University dental school.

Other suggestions to improve fifth-year students' competence include adding teeth extractions to the clinical procedures of the competent level for fifth-year students and perhaps replace esthetic crowns. Performing teeth extractions is very often a needed procedure, regardless of the student's academic level, as well as a commonly performed one by a general dentist in the dental practice, as compared to esthetic crowns, which are commonly performed by specialists. This change seems to be necessary, particularly when the prevalent nature of dental caries in children is considered in the Saudi community. Also, the likelihood of fifthyear students performing stainless steel crowns should be increased. Dental students should be taught the "Hall technique", which is a less demanding technique for stainless steel crown placement in children, as well as reported to be preferred to conventional restorations by children, their parents, and even general dentists $[12,16]$. Several dental schools are now teaching the "Hall technique" for dental students to increase the chances of students gaining experience in this clinical skill $[11,12]$.

In the present study, females had significantly higher mean competency scores than males in the clinical skills; examination, diagnosis, and treatment planning of child patients, restorations, stainless steel crowns for primary molars, and esthetic crowns. Females also had higher overall mean competency scores than males; however, the difference was insignificant. This finding is consistent with a previous study that found that females outscored males in some clinical courses, which included pediatric dentistry [17]. That was attributed to a greater willingness of female students to treat children than males $[17,18]$.

Finally, it is important to address the limitations of the present study; one important limitation is that the present study did not assess the self-assessed confidence of the undergraduate dental students in pediatric dentistry. Having sufficient confidence in providing dental care for children is an important learning outcome of any course [11]. Also, the students' self-assessed-confidence in their clinical skills can differ from their actual scores [19]. Consequently, a future study to assess the self-assessed competence of undergraduate dental students and its correlation with actual clinical competence in pediatric dentistry seems to be needed. 


\section{Conclusion}

The fourth-year dental students at Qassim University dental school were more competent clinically than fifth-year students in pediatric dentistry. Also, females were more competent than males in most of the shared clinical procedures. A deficiency in the clinical competence of fifth-year students was particularly noted in the clinical procedures, which included pulp therapy, stainless steel crowns of primary molars, and esthetic crowns, and these issues are currently being addressed.

\section{Authors' Contributions} SNA (D) https://orcid.org/O000-0001-5210-5128 Conceptualization, Methodology, Validation, Formal Analysis, Investigation, Data Curation,
Writing - Original Draft, Writing - Review and Editing and Visualization.

\section{Financial Support}

None.

\section{Conflict of Interest}

The authors declare no conflicts of interest.

\section{Data Availability}

The data used to support the findings of this study can be made available upon request to the corresponding author.

\section{References}

[1] World Health Organization. Sugars and dental caries. WHO technical information note. 2017. Available from: https://apps.who.int/iris/bitstream/handle/10665/259413/WHO-NMH-NHD-17.12-eng.pdf? sequence=1. [Accessed on November 16, 2020].

[2] Al-Malik MI, Holt RD, Bedi, R. Prevalence and patterns of caries, rampant caries, and oral health in two- to fiveyear-old children in Saudi Arabia. J Dent Child 2003; 70(3):235-42.

[3] Al-Haj Ali SN, Alshabaan SH. What do parents know about oral health and care for preschool children in the central region of Saudi Arabia? Pesqui Bras Odontopediatria Clín Integr 2020; $20: e 0103$. https://doi.org/10.1590/pboci.2020.166

[4] Alhabdan YA, Albeshr AG, Yenugadhati N, Jradi H. Prevalence of dental caries and associated factors among primary school children: a population-based cross-sectional study in Riyadh, Saudi Arabia. Environ Health Prev Med 2018; 23(1):60. https://doi.org/10.1186/s12199-018-0750-Z

[5] Al-Ogayyel S, Al-Haj Ali S. Comparison of dental treatment performed under general anesthesia between healthy children and children with special health care needs in a hospital setting, Saudi Arabia. J Clin Exp Dent 2018; 10(10):e963-69. https://doi.org/10.4317/jced.55060

[6] Aldhilan S, Al-Haj Ali S. Approaches used to care for carious primary mollars among pediatric dentists and general dental practitioners in Saudi Arabia. J Clin Exp Dent 2018; 10(3):e2 12-17. https://doi.org/10.4317/jced.54453

[7] Rich JP 3rd, Straffon L, Inglehart MR. General dentists and pediatric dental patients: the role of dental education. J Dent Educ 2006; 70(12):1308-15.

[8] Stewart CJ, Moloney EJ, Kinirons MJ. Clinical experiences of undergraduate dental students in pediatric dentistry at Cork University Dental School and Hospital, Ireland. J Dent Educ 2010; 74(3):325-30.

[9] Plasschaert A, Manogue M, Lindh C, McLoughlin J, Murtomaa H, Nattestad A, et al. Curriculum content, structure, and ECTS for European dental schools. Part II: methods of learning and teaching, assessment procedures, and performance criteria. Eur J Dent Educ 2007; 11(3):125-36. https://doi.org/10.1111/j.1600-0579.2007.00445.x

[10] Seale NS, Casamassimo PS. U.S. predoctoral education in pediatric dentistry: its impact on access to dental care. J Dent Educ 2003; 67(1):23-30.

[11] Sonbol HN, Abu-Ghazaleh SB, Al-Bitar ZB. Undergraduate experience and self-assessed confidence in paediatric dentistry at the University of Jordan Dental School. Eur J Dent Educ 2017; 21(4):e126-30. https://doi.org/10.1111/eje.12233

[12] Rodd HD, Farman M, Albadri S, Mackie IC. Undergraduate experience and self-assessed confidence in paediatric dentistry: comparison of three UK dental schools. $\mathrm{Br}$ Dent J 2010; 208(5):221-5. https://doi.org/10.1038/sj.bdj.2010.207 
[13] Seddon RP. Undergraduate experience of clinical procedures in paediatric dentistry in a UK dental school during 1997-2001. Eur J Dent Educ 2004; 8(4):172-6. https://doi.org/10.1111/j.1600-0579.2004.00346.x

[14] American Academy of Pediatric Dentistry. Policy on the Role of Dental Prophylaxis in Pediatric Dentistry. Pediatr Dent 2018; 40:47-8.

[15] American Academy of Pediatric Dentistry. Periodicity of Examination, Preventive Dental Services, Anticipatory Guidance/Counseling, and Oral Treatment for Infants, Children, and Adolescents. Pediatr Dent 2018; 40:194-204.

[16] Innes NP, Evans DJ, Stirrups DR. The Hall technique is an effective treatment option for carious primary molar teeth. Evid Based Dent 2007; 9:44-5.

[17] Sawair FA, Baqain ZH, Al-Omari IKh, Wahab FK, Rajab LD. Effect of gender on performance of undergraduate dental students at the University of Jordan, Amman. J Dent Educ 2009; 73(11):1313-9.

[18] Buddeberg-Fischer B, Klaghofer R, Abel T, Buddeberg C. Swiss residents' specialty choices: impact of gender, personality traits, career motivation and life goals. BMC Health Serv Res 2006; 6:137. https://doi.org/10.1186/1472-6963-6-137

[19] Baxter P, Norman G. Self-assessment or self deception? A lack of association between nursing students' selfassessment and performance. J Adv Nurs 2011; 67(11):2406-13. https://doi.org/10.1111/j.1365-2648.2011.05658.x 